\title{
From Codivilla to Ponseti: historical narrative review on clubfoot treatment in Italy
}

\author{
Flavia Alberghina ${ }^{1} \wedge$, Gianluca Testa $^{2} \wedge$, Sergio Monforte $^{3 \wedge}$, Vito Pavone $^{2} \wedge$, Antonio Andreacchio ${ }^{3} \wedge$ \\ ${ }^{1}$ Department of Orthopedics and Traumatology, "CTO” Hospital, University of Turin, Torino, Italy; ${ }^{2}$ Department of General Surgery and Medical \\ Surgical Specialties, Section of Orthopedics and Traumatology, A.O.U. Policlinico "Rodolico - San Marco", University of Catania, Catania, Italy; \\ ${ }^{3}$ Pediatric Orthopedic Surgery Department, “Buzzi” Children's Hospital, Milano, Italy \\ Contributions: (I) Conception and design: All authors; (II) Administrative support: A Andreacchio, V Pavone; (III) Provision of study materials or \\ patients: All authors; (IV) Collection and assembly of data: F Alberghina, G Testa; (V) Data analysis and interpretation: All authors; (VI) Manuscript \\ writing: All authors; (VII) Final approval of manuscript: All authors. \\ Correspondence to: Antonio Andreacchio. Pediatric Orthopedic Surgery Department, "Vittore Buzzi” Children's Hospital, Via Lodovico Castelvetro \\ 32, 20154, Milano, Italy. Email: a.andreacchio@libero.it.
}

\begin{abstract}
Objective: This narrative review aims to summarize the historical steps of clubfoot treatment in Italy, identifying the centuries-old historical advancement in the deformity management and the most influent involved people.

Background: Clubfoot, also referred to as congenital talipes equinovarus, is a relatively common deformity that has significative consequences in the child if it is left untreated. Effective and early treatment of clubfoot has been praised as one of the most successful practice of modern pediatric orthopedics and both surgical and conservative techniques have been proposed over the decades. As an example, Codivilla's posteromedial release (PMR) has been known internationally as one of the milestones of surgical treatment.

Methods: The narrative review includes clinical studies and reviews concerning clubfoot that were written in English, German and Italian. As an historical review, no limits of years were considered. The search was performed using PubMed, Google Scholar, Scopus, Medline and Cochrane Library databases up to January 2021. A combination of search terms including 'history', 'clubfoot', 'conservative management', 'Codivilla', 'Ponseti method', 'relapse' was utilized. Particular attention was given to papers written by Italian authors.

Conclusions: Current clubfoot treatment arises from several studies and clinical research over the centuries. Many surgeons, starting from mid-16th century, have studied the deformity trying to find a successful and effective technique to achieve full correction. Italian scientists, surgeons and prestigious institutions surely took part in this process.
\end{abstract}

Keywords: Clubfoot; history; treatment; Codivilla; Ponseti

Submitted Dec 13, 2020. Accepted for publication Mar 31, 2021.

doi: 10.21037/atm-20-7956

View this article at: http://dx.doi.org/10.21037/atm-20-7956

\section{Introduction}

Idiopathic clubfoot, also referred to as congenital talipes equinovarus, is one of the most common lower limb deformities observed in newborns, occurring at 1 to 2 per
1,000 births. Over the centuries, the exact etiology of IC still remains unclear, however a combination of genetic and environmental factors are hypothesized to play a role in the pathogenesis. It is characterized by three dimensional deformities including forefoot adductus, midfoot cavus,

^ ORCID: Flavia Alberghina, 0000-0003-0125-6983; Gianluca Testa, 0000-0001-5944-4341; Sergio Monforte, 0000-0003-3391-6659; Vito Pavone, 0000-0001-5664-8066; Antonio Andreacchio, 0000-0001-7729-3890. 
hindfoot varus, and ankle equinus. When left untreated, clubfoot may cause a severe impairment of the lower extremity, resulting in a significant level of disability due to the pain, stiffness, and gait disturbance.

Many treatment techniques either conservative, surgical or hybrid have been used over centuries. This review aims to summarize the historical steps of clubfoot treatment in Italy, outlining the centuries-old history of advancement in the deformity management and the most influent people involved.

We present the following article in accordance with the Narrative Review reporting checklist (available at http:// dx.doi.org/10.21037/atm-20-7956).

\section{Sources}

The narrative review includes clinical studies and reviews concerning clubfoot that were written in English, German and Italian. As an historical review, no limits of years were considered. The search was performed using PubMed, Google Scholar, Scopus, Medline and Cochrane Library databases up to January 2021. A combination of search terms including 'history', 'clubfoot', 'conservative management', 'Codivilla', 'Ponseti method', 'relapse' was utilized. A bibliographic research was also performed in library archives at our institutions. Particular attention was given to papers written by Italian authors.

\section{The early days of clubfoot treatment}

An awareness of the disorder has long been known since ancient times. The deformity was first illustrated in ancient Egyptian tomb paintings and traces of its treatment were described in the Indian Ajur-Veda as early as 1000 B.C. (1). The etiology was firstly postulated by Hippocrates (400 B.C.), who believed the caused factor to be a mechanical external pressure on the fetal foot (2). The theory has been upheld by Galen and by modern authors (3) and is still valid today at least for the positional foot deformities. Hippocrates also defined the basis of clubfoot treatment, recommending repeated manipulation and fixation by bandages, and urging to start as soon as possible after birth (4).

Over the years the etiology of the condition alongside anatomy, pathology, and clinical presentation has been deeply investigated and different treatment techniques have been worldwide described (5-8).

In the $16^{\text {th }}$ century the Italian anatomist Gabriele Falloppio (1523-1562) from Modena, contributed to better understand the treatment of clubfoot, describing day by day correction after preliminary hot baths and poultices. This practice was thought to be useful in soften the tissues, so after a week or two the child could be ready for manipulation. The surgeon then restored the proper shape of the affected foot "with great force" and applied soft bandages reinforced by malleable wooden splints bandaged overall (4). Subsequently, a metal splintage and special shoes were used, recognizing already the potential advantages of gradual correction.

A pupil of Falloppio, Girolamo Fabrici d'Acquapendente (1533-1619) from Padua, continued the studies of his mentor. Known as the father of embryology, he confirmed that the deformity might be related to an embryonic stage of development and created specific devices to treat clubfoot (9).

Antonio Scarpa from Pavia, in 1803, first described the pathological anatomy of clubfoot (10). According to his studies, in clubfoot tarsal bones but talus were misshapen and smaller than normal feet and their anatomic relations altered. He considered the deformity due to a dislocation of the forefoot inward upon the head of the talus, being the talus almost normal both in position and shape. $\mathrm{He}$ believed in an ambulatory treatment based on manipulation to correct the varus deformity, followed by application of a peculiar brace incorporating steel springs, later known as Scarpa's shoe.

Despite the first reports on treatment focused on manipulation and stretching, the variable success of the attempts has led different authors to be more aggressive starting to use surgical techniques to achieve an adequate correction.

On the other hand, in the $18^{\text {th }}$ century the use of plaster of Paris was introduced. In particular, Antonius Mathijsen (1805-1878) from Netherlands invented the first modern plaster-of-Paris bandage in 1852, but was the compatriot Blumenkamp, in the following year, who firstly adapted the bandage to clubfoot (4).

\section{Alessandro Codivilla and the "Surgical Period"}

From the mid- $19^{\text {th }}$ century onwards, many surgeons gave their contribute to the so-called surgical period. An example was given in 1888 by Agustoni from Milan who described 23 cases of talectomy performed in clubfoot patients (11). In 1905 , at the ' $18^{\text {th }}$ Meeting of the Italian Society of Surgery', Alessandro Codivilla (1861-1912) (Figure 1) from Bologna presented his surgical technique published later in his work titled "Nuovo metodo di cura cruenta del piede 


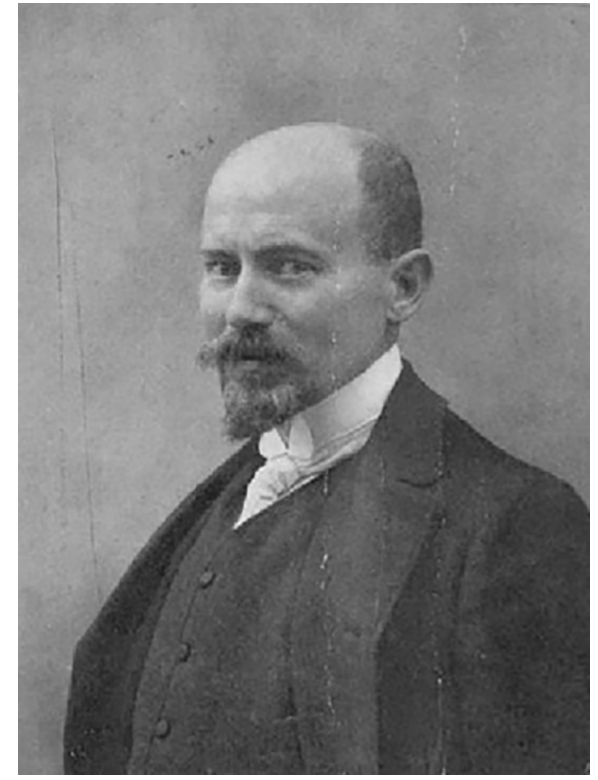

Figure 1 Photographic portrait of Alessandro Codivilla. Reprinted with permission of Cappelli Editore from "Scritti Medici di Alessandro Codivilla”, Putti V, 1913.

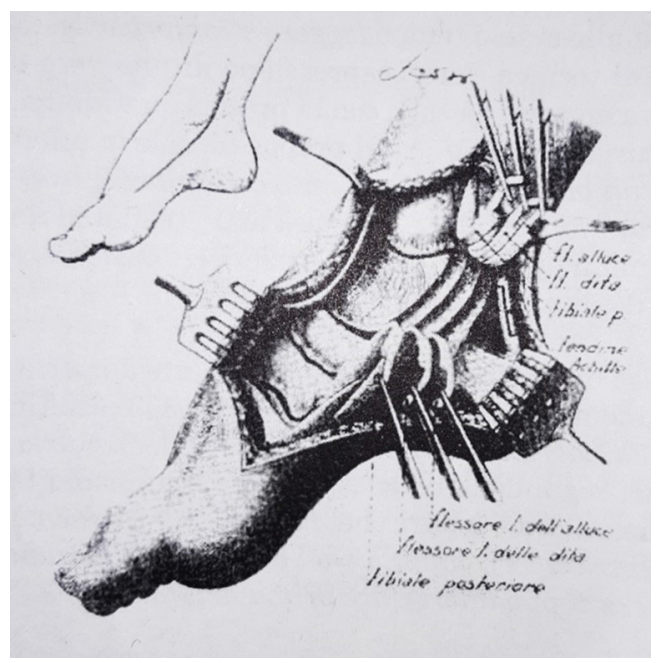

Figure 2 Illustration of the Codivilla's procedure. Reprinted with permission of Cappelli Editore from "Scritti Medici di Alessandro Codivilla”, Putti V, 1913.

equino varo congenito" (12). Thanks to his remarkable scientific and surgical skills, he became director of Rizzoli Orthopedics Institute in Bologna and published more than one hundred papers, reporting innovative techniques to treat various conditions such as polio residuals, scoliosis, and congenital dislocation of the hip. However, he considerably contributed to the development of clubfoot surgical treatment, being among the first surgeons to use functional tenodesis, tendon lengthening and osteotomies, to correct complex foot deformities $(12,13)$. In later years, his standardized surgical procedure was known, firstly in Italy and then abroad, as the "Codivilla procedure" and it is still seldom performed nowadays (Figure 2).

In early 1900' additional release of the posterior capsule of the ankle had been already described, being known that simple elongation of the Achilles tendon was not sufficient to correct the equinovarus deformity (14). According to Codivilla, to achieve the correction also elongation of the tibialis posterior (TP), flexor digitorum longus (FDL), and flexor hallucis longus (FHL) were needed at the time of Achilles tendon lengthening. His surgical technique consists of two stages: firstly, the joints affected by the deformity are opened and shaped; secondly, tendon and muscular elongation is performed.

In particular, the procedure includes (12): (I) lengthening of the Achilles tendon; (II) excision of the posterior capsule of the ankle joint, of the posteromedial capsule of the subtalar joint, and of the talonavicular joint; (III) excision of the superficial part of the deltoid ligament and the medial part of the spring ligament; (IV) Z-shaped lengthening of PT, FDL and FHL. The achieved correction is then fixed by two Kirschner wires: one plantar, used to maintain the reduction of varus and equinus, drilled trough the subtalar joint into the tibia; the other for the reduction of forefoot and talonavicular adduction, drilled into the medial arch, passing through the first metatarsal, the first cuneiform, navicular and talus.

At the end of surgery, a toe-to-groin plaster cast with the knee flexed at $90^{\circ}$ and with the foot in maximum dorsiflexion, abduction and pronation is applied for 6 weeks. At cast removal, an aluminum brace holding the foot in the corrected position was applied full time until the child starts to walk, and afterwards at night only until 3 years of age.

Being recognized as tools to make the treatment easier, similar external orthopaedic devices were generating interest, i.e., Osteoclast created and used by Vittorio Putti at Rizzoli Orthopedics Institute in Bologna (15).

Codivilla's work inspired many surgeons interested in the correction of foot deformities. Francesco Delitala, in 1940, wrote about the above-mentioned procedure: 'The operation of Codivilla is one of the bases of Orthopedics: it's useless to try to change it, it is born perfect' (16).

Nevertheless, Vincent J. Turco is credited with 
describing the first complete one-stage posteromedial release (PMR) in 1971 (17). Both Codivilla's and Turco's techniques start with a single medial incision and include Achilles tendon lengthening, PT lengthening and fixation with two Kirschner wires. However, in Codivilla's PMR, Z-shaped lengthening of FDL and FHL is also performed, whereas in Turco's procedure only the sheaths of these tendons are incised (17).

Between 1968 and 1975, Turra et al. compared 91 feet in 68 patients underwent Codivilla's operation and Turco's modification. Based on their findings, Turco's modification of the classical Codivilla operation enhances the results of PMR (18).

Pazzaglia et al. form Pavia (19) reviewed 30 clubfoot patients treated surgically by a slightly modified Codivilla technique. Clinical, functional, and radiographic followup was performed an average of 10 years after the surgery. The outcome was rated good in $41 \%$ of the cases, fair in $29 \%$, and unsatisfactory in $30 \%$. The authors found a close correlation between the grade of the initial deformity and the final outcome, observing that some signs of the deformity remained anyway, even when the functional outcome was excellent.

Due to the controversial outcome of extensive surgical release and the high rate of poor functional results with painful, stiff and arthritic feet $(20,21)$, in some centers, after the initial enthusiasm for surgical correction, conservative methods returned to be considered as the core of the treatment.

\section{Back to manipulation}

Carlo Marino-Zuco from Rome, in 1934, had published his work about clubfoot manipulation and casting in newborns (22). Manipulation was followed by application of serial toe-to-groin plaster cast, with the knee flexed at $90^{\circ}$, started around the ten days after birth. The foot was corrected by abducting and pronating the forefoot, pushing downwards the first metatarsal to the level of the fifth, to achieve a plantigrade position of the foot. An opposite pressure was exerted on the anterior tuberosity of the calcaneus, grasped with the other caster's hand.

Plaster casts were changed weekly for 5-7 weeks, and then every 2-3 weeks until 3-5 months of age. After cast phase, a gentle correction of equinus and varus of the heel was started, by exerting counterpressure on the posterolateral aspect of the fibular malleolus.

In the same period, a similar technique proposed by the American John Hiram Kite (1891-1986) working at the Atlanta Scottish Rite Hospital, was gaining popularity and receiving international consensus. Kite's innovative contribution was the conception and establishment of the principle that each component of clubfoot deformity had to be addressed and treated individually according to a strict order: first, the forefoot adduction, followed by hindfoot varus and equinus, and finally the cavus (23). Therefore, the main criticism to Kite's method was the long correction time.

Ricciardi-Pollini et al. (24) reported the outcome of 47 congenital club feet treated with Marino-Zuco protocol, observing 24\% cases of relapse at a mean age of 6 years. Moreover, club feet treated with additional posterior release had a relapse in $12 \%$ of the cases, while $70 \%$ of those treated with PMR relapsed.

\section{Ponseti method}

Ponseti method represents the most innovative change in clubfoot approach. It was ideated by Ignacio Vives Ponseti, a Spanish orthopaedic surgeon, migrated to Mexico in 1939 during Franco's domination, and arrived at University of Iowa in 1941, location recognized as to be excellent orthopaedic training center (25). At University of Iowa he studied the outcomes of clubfoot surgery over a 20-year period, finding a lot of unsatisfactory results after open surgery. For this reason, he focused his studies to find and promote less invasive techniques. Ponseti developed his method of clubfoot correction in 1948, and published his first clinical outcome study in 1963; studying the anatomo-pathology of clubfoot, he understood the importance of inversion of the foot, meaning that the growth of the clubfoot might be negatively influenced by the abnormal pressure of displaced navicular on talus ossification center (26).

His protocol consists of two phases: treatment and maintenance. The first should be started as early as possible, within the first three weeks of life. However, a delay in starting the treatment doesn't compromise the outcome (8). The physician performs gentle manipulation and casting weekly, addressing the different components of the deformity in sequence, starting from the cavus. Subsequently, the abduction of the forefoot, while using the head of the talus as the fulcrum, results in the correction of the midfoot adduction deformity together with the hindfoot varus and the subtalar component of the equinus deformity. After four to five casts, more than $80 \%$ of infants needs a percutaneous Achilles tendon tenotomy to correct the residual equinus. The maintenance phase consists in placing 
a Denis-Browne brace to maintain the achieved correction and avoid relapse. The orthosis should be worn 23 hours per day for three months and then, the number of hours of bracing during daily life should progressively decrease until 4-5 years of age $(27,28)$.

From 1980's, Prof. Ernesto Ippolito from Rome has shown significant interest in congenital clubfoot. Together with Ponseti at University of Iowa, he focused his researches on anatomopathological features, reporting the possibility of a retracting fibrosis as the primary etiological factor of the clubfoot deformity (4). Being among the first promoters of the Ponseti method in Italy, Prof. Ippolito reported, in 1984, the results (24) of the first Italian patient series treated by Ponseti method (26). Additionally, his group conducted a comparative study, using CT scan, between 96 clubfeet and 45 normal feet at skeletal maturity treated with two different protocols; as a result, Ponseti manipulative technique, in comparison with the extensive medial release associated with the traditional manipulative technique, achieved better alignment of the forefoot on the hindfoot, without excessive externally rotation of the ankle mortice (29). In 2009, the validity of this mini-invasive technique was confirmed by Farsetti et al. (30), comparing Ponseti method to the old manipulative and casting technique according to MarinoZuco and Codivilla's postero-medial release: Ponseti method group reported normal torsion angle of the ankle and talar body-neck angle, underlining its superiority, compared to the traditional technique.

The use of the method started to become widely spread in all regions of Italy.

To emphasize the growing interest in the affection, the first congress of the Italian Paediatric Orthopaedic and Traumatology Society (SITOP), held in 1985, focused on clubfoot, and this trend was repeated in many of the following. In 2001, Prof. Ignacio Ponseti and Prof. Henry Bensahel were special guests presenting their own methods. Yet, in 2006, the first SITOP update on Ponseti method took place in Rome, recognizing the technique as gold standard for the treatment of clubfoot.

In 2013, Pavone et al. (31) reported a case series of 114 patients treated with Ponseti method showing, after 4-year mean follow-up, excellent results or good in $96 \%$ of clubfeet, with a recurrence rate of $4.5 \%$.

In 2016, Faldini et al. (32) published their study on 88 clubfeet treated with Ponseti method, considering the difference in starting the treatment before or during walking-age; in their experience, newborns and non-walking children may be more successfully treated with serial casting than walking children, underlining the importance of starting treatment at birth to achieve good outcomes. However, even that nonsurgical treatment is less effective during and after walking age, re-casting with the Ponseti technique remain a valuable mean to limit the invasiveness of surgical procedures in older children.

Recently, Lampasi et al. (33) described the progression of clinical correction in clubfeet treated with Ponseti method, confirming that the technique basically works as originally anticipated; the frequency of muscle imbalance (i.e., weakness of peroneal muscles) in clubfoot has a great influence on progression of correction, and should be monitored in their evolution. The same group described the progression of clubfoot correction using Ponseti method, individuating the Pirani score as a guide to indication for tenotomy (34); this finding confirmed the statistical significance between initial severity Pirani score and necessity of tenotomy, reported also by Pavone et al. (31).

Trying to avoid surgical correction, Persiani et al. used the Ponseti method in patients with Osteogenesis imperfecta and clubfoot, carefully respecting the bone weakness typical of these patients, and treating also very severe clubfeet (35). In particular, they used a modified Ponseti technique, consisting in progressive castings for longer periods (36). However, when poor compliance was evident, surgical correction was performed as soon as possible, in order to avoid complications such as stiffness (35).

In 2019, Gigante et al. from Padua (37) proposed an innovative casting technique, to reduce risks of malpractice and complication in clubfoot patients. A modified posterior above-knee cast was applied in 70 clubfeet, with the anterior leg and thigh free from the direct contact with the cast. The main advantages were the faster and easier removal, using common scissors, especially in case of acute peripheral disturbance. In his series, full correction was obtained in $93 \%$ of cases clubfoot after a mean treatment duration of 50 days.

In the same year, Dibello et al. from Trieste (38), underlined the importance of prenatal diagnosis and counselling in families expecting a baby with clubfoot. Making aware the parents about the affection and the stages of Ponseti protocol, the compliance is potentially increased and the family is better prepared towards the early onset of treatment and the correct use of the brace.

Overall, all mentioned studies confirm that Ponseti method offers good results at mid- and log-term followup, leading to a plantigrade foot with normal aspect and function, comparable to a normal foot. As a result, 
Ponseti Method is nowadays the most popular technique for clubfoot management and Italian pediatric orthopedic centers have been following this trend.

\section{Treatment of relapses}

Relapse represents the most common complication in clubfoot treatment, even in congenital clubfeet fully corrected since the first month of life (24,26,39-41).

It could often occur before the fifth year of age being related to the pathological structure of the foot, but it could also appear after this age. Clinical signs are small calf size, slight equinus, and progressive stiffness. In 2006, Farsetti et al. (42) reported the first Italian series on relapsing deformity treatment; they described a technique of correction in eversion for both dynamic and flexible deformities. In cases of uncorrectable feet in eversion, the transfer of the anterior tibialis tendon was added,

In 2010, Lampasi et al. (43) compared the anterior tibialis tendon transfer to other corrective procedures, finding that extensive surgery has a higher rate of poor results and failures, stiffness, and re-operations. So, anterior tibialis tendon transfer must be indicated only in cases of muscle imbalance and eversion impairment. The same authors strongly recommended to locate the anterior tibialis tendon beneath the extensor retinaculum. In 2014, the same group reported a case report (44) of a stress fracture of the fourth metatarsal bone in a relapsed clubfoot of a 5.5 -year-old child, highlighting the occurrence of this complication being related to imbalance between remodeling and axial deviation; this was a confirmation for the necessity of early correction of the deformity.

In 2016, the validity of Ponseti Method re-application in relapses after walking age was evidenced by another study published by Dragoni et al. at Tor Vergata University in Rome (45). In a series of 79 relapsed clubfeet, initially treated with three different methods, they observed that a modified Ponseti Method (5 to 10 minutes of manipulations, increased cast duration up to 3 weeks and additional tibial anterior tendon transfer) is effective in the treatment of rigid residual deformity in children from 2 to 8 years of age, with superior results than other surgical procedures, as extensive soft-tissue and/or osseous procedures. Improvements were immediately evident after the first cast, and this was a factor increasing the parents' compliance; otherwise, re-application of long leg casts represented a major problem in limitation of walking ability.

Treatment of clubfoot relapse is also possible in young adults. In 2018, in their study, Riganti et al. at Gaslini Institute of Genoa reported a series of adolescents with complex foot deformities, including clubfoot relapses, treated using distraction osteogenesis and hexapod systems (46). This study showed that external fixation is a feasible and safe alternative method able to achieve correction of multiplanar deformities and a subsequent normal sized foot. However, experience in external fixation techniques, good compliance and strict follow-up are necessary to avoid the high rate of complications.

\section{Summary}

Current clubfoot treatment is based on several studies and clinical research over the centuries. Many surgeons, starting from mid- $16^{\text {th }}$ century, have studied the deformity trying to find a successful and effective technique to achieve its correction. Historically, in Italy, there were several dedicated scientists in different prestigious Institutions who tried to deep the knowledge on the affection. Many surgeons focused their attention to develop surgical techniques, perhaps more than in other Countries, so an attitude to privilege the surgical solution for clubfoot was evident from our narrative review. On the other hand, even in the US when Ponseti published his reports, there was a strong skeptical attitude to accept the conservative method. Nowadays the scientific progress and the Evidence Based Medicine have demonstrated the minimally invasive Ponseti method to be safe, cheap, reproducible and effective. Moreover, WHO recognized this conservative technique as the gold standard for the treatment of clubfoot. It requires a learning curve and the main pediatric center should have few doctors skilled in this method. Most importantly, taking care of the technical casting details and enhancing the adherence to the brace are the keys of the treatment success.

\section{Acknowledgments}

Funding: None.

\section{Footnote}

Provenance and Peer Review: This article was commissioned by the Guest Editors (Federico Canavese and Alain Dimeglio) for the series "Clubfoot" published in Annals of Translational Medicine. The article has undergone external peer review.

Reporting Checklist: The authors have completed the 
Narrative Review reporting checklist. Available at http:// dx.doi.org/10.21037/atm-20-7956

Conflicts of Interest: All authors have completed the ICMJE uniform disclosure form (available at http://dx.doi. org/10.21037/atm-20-7956). The series "Clubfoot" was commissioned by the editorial office without any funding or sponsorship. The authors have no other conflicts of interest to declare.

Ethical Statement: The authors are accountable for all aspect of the work in ensuring that questions related to the accuracy or integrity of any part of the work are appropriately investigated and resolved.

Open Access Statement: This is an Open Access article distributed in accordance with the Creative Commons Attribution-NonCommercial-NoDerivs 4.0 International License (CC BY-NC-ND 4.0), which permits the noncommercial replication and distribution of the article with the strict proviso that no changes or edits are made and the original work is properly cited (including links to both the formal publication through the relevant DOI and the license). See: https://creativecommons.org/licenses/by-nc-nd/4.0/.

\section{References}

1. Strach EH. Club-foot through the centuries. Prog Pediatr Surg 1986;20:215-37.

2. Dobbs MB, Morcuende JA, Gurnett CA, et al. Treatment of idiopathic clubfoot: an historical review. Iowa Orthop J 2000;20:59-64.

3. Browne D. Talipes equino-varus. Lancet 1934;224.5801:969-74.

4. Hernigou P, Huys M, Pariat, J, et al. History of clubfoot treatment, part I: From manipulation in antiquity to splint and plaster in Renaissance before tenotomy. Int Orthop 2017;41:1693-704.

5. Parker RW, Shattock SG. The pathology and etiology of congenital club-foot. Pathological Society of London. 1884.

6. Ippolito E, Ponseti IV. Congenital clubfoot in the human fetus: a histological study. J Bone Joint Surg Am 1980;62:8-22.

7. Ponseti IV. Congenital clubfoot. Fundamentals of treatment. Oxford: Oxford University Press, 1996;41:76-123.

8. Radler C. The Ponseti method for the treatment of congenital club foot: review of the current literature and treatment recommendations. Int Orthop 2013;37:1747-53.

9. Fabricius ab Aquapendente H. Opera cirurgica. Frankfurt. 1592. Available online: https:// hagstromerlibrary.ki.se/books $/ 5617$

10. Scarpa A. A memoir on the congenital club feet of children, and of the mode of correcting that deformity. 1818. Clin Orthop Relat Res 1994;(308):4-7.

11. Agustoni A. Ventitré casi di estirpazione dell'astragalo per la correzione del piede torto. Archivio di ortopedia 1888;5:172-82.

12. Codivilla A. A new surgical treatment for congenital clubfoot. Arch Orthop 1906;23:245-58.

13. Brand RA. Advances in limb lengthening and reconstruction: Alessandro Codivilla, MD, 1861-1912. Clin Orthop Relat Res 2008;466:2901-2.

14. Zadek I, Barnett E. The importance of the ligaments of the ankle in correction of congenital clubfoot. JAMA 1917;69:1057.

15. Delitala F, Scaglietti O. Scritti Medici by Vittorio Putti. Schematic representation of Osteoclast. Edizioni Scientifiche Istituto Rizzoli, Bologna. 1952. Available online: https://voyagercatalog.kumc.edu/Record/147960

16. Sanzarello I, Nanni M, Faldini C. The clubfoot over the centuries. J Pediatr Orthop B 2017;26:143-51.

17. Turco VJ. Surgical correction of the resistant club foot. One-stage posteromedial release with internal fixation: a preliminary report. J Bone Joint Surg Am 1971;53:477.

18. Turra S, Pavanini G, Volpe A. Surgical treatment of congenital club foot. (Comparison of the results of Codivilla's operation with those of Turco's modification). Ital J Orthop Traumatol 1978;4:155-69.

19. Pazzaglia UE, Riccardi C, Valle L, et al. Clinical and radiographic evaluation of the Codivilla method of surgical correction of congenital club foot. Medium-term followup of 235 cases. Ital J Orthop Traumatol 1992;18:371-8.

20. Cooper DM, Dietz FR. Treatment of idiopathic clubfoot. A thirty-year follow-up note. J Bone Joint Surg Am 1995;77:1477-89.

21. Dimeglio A, Canavese F. The French functional physical therapy method for the treatment of congenital clubfoot. J Pediatr Orthop B 2012;21:28-39.

22. Marino-Zuco C. Trattamento del piede torto congenito. Rome: Arte della Stampa, 1934:12-27.

23. Kite JH. Nonoperative treatment of congenital clubfoot. Clin Orthop Relat Res 1972;84:29-38.

24. Ricciardi-Pollini PT, Ippolito E, Tudisco C, et al. Congenital clubfoot: results of treatment of 54 cases. Foot Ankle 1984;5:107-17. 
25. Hernigou P. History of clubfoot treatment; part III (twentieth century): back to the future. Int Orthop (SICOT) 2017;41:2407-14.

26. Ponseti IV, Smoley EN. Congenital clubfoot: the results of treatment. J Bone Joint Surg Am 1963;45:261-344.

27. Laaveg SJ, Ponseti IV. Long-term results of treatment of congenital clubfoot. J Bone Joint Surg Am 1980;62:23-31.

28. Ponseti IV. Clubfoot Management. Editorial. J Pediatr Orthop 2000;20:699-700.

29. Ippolito E, Fraracci L, Farsetti P, et al. The influence of treatment on the pathology of club foot. CT study at maturity. J Bone Joint Surg Br 2004;86:574-80.

30. Farsetti P, De Maio F, Russolillo L, et al. CT study on the effect of different treatment protocols for clubfoot pathology. Clin Orthop Relat Res 2009;467:1243-9.

31. Pavone V, Testa G, Costarella L, et al. Congenital idiopathic talipes equinovarus: an evaluation in infants treated by the Ponseti method. Eur Rev Med Pharmacol Sci 2013;17:2675-9.

32. Faldini C, Traina F, Nanni M, et al. Congenital idiopathic talipes equinovarus before and after walking age: observations and strategy of treatment from a series of 88 cases. J Orthop Traumatol 2016;17:81-7.

33. Lampasi M, Trisolino G, Abati CN, et al. Evolution of clubfoot deformity and muscle abnormality in the Ponseti method: evaluation with the Dimeglio score. Int Orthop 2016;40:2199-205.

34. Lampasi M, Abati CN, Stilli S, et al. Use of the Pirani score in monitoring progression of correction and in guiding indications for tenotomy in the Ponseti method: Are we coming to the same decisions? J Orthop Surg (Hong Kong) 2017;25:2309499017713916.

35. Persiani P, Ranaldi FM, Martini L, et al. Osteogenesis imperfecta and clubfoot-a rare combination: Case report and review of the literature. Medicine (Baltimore) 2016;95:e4505.

36. Ponseti IV, Zhivkov M, Davis N, et al. Treatment of the complex idiopathic clubfoot. Clin Orthop Relat Res

Cite this article as: Alberghina F, Testa G, Monforte S, Pavone V, Andreacchio A. From Codivilla to Ponseti: historical narrative review on clubfoot treatment in Italy. Ann Transl Med 2021;9(13):1108. doi: 10.21037/atm-20-7956
2006;451:171-6.

37. Gigante C, Pedrotti L, Guido D. Proposal of an innovative casting technique for correction of clubfoot according to Ponseti method: a pilot study. J Pediatr Orthop B 2019;28:242-7.

38. Dibello D, Colin G, Galimberti AMC, et al. Ten year challenge with Ponseti method for clubfoot: our experience. Acta Biomed 2019;90:127-30.

39. Bensahel H, Catterall A, Di Meglio A. Practical applications in idiopathic clubfoot: a retrospective multicentric study in EPOS. J Pediatr Orthop 1990;10:186-8.

40. Ippolito E, Ricciardi-Pollini PT, Tudisco C, et al. The treatment of relapsing club-foot by tibialis anterior transfer underneath the extensor retinaculum. Ital J Orthop Traumatol 1985;11:171-7.

41. Morcuende JA, Dolan LA, Dietz FR, et al. Radical reduction in the rate of extensive corrective surgery for clubfoot using the Ponseti method. Pediatrics 2004;113:376-80.

42. Farsetti P, Caterini R, Mancini F, et al. Anterior tibial tendon transfer in relapsing congenital clubfoot: longterm follow-up study of two series treated with a different protocol. J Pediatr Orthop 2006;26:83-90.

43. Lampasi M, Bettuzzi C, Palmonari M, et al. Transfer of the tendon of tibialis anterior in relapsed congenital clubfoot: long-term results in 38 feet. J Bone Joint Surg Br 2010;92:277-83.

44. Lampasi M, Tavernini T, Donzelli O. Stress fracture of the fourth metatarsal in a relapsed clubfoot of a 5.5-year-old child. Musculoskelet Surg 2014;98:159-63.

45. Dragoni M, Farsetti P, Vena G, et al. Ponseti Treatment of Rigid Residual Deformity in Congenital Clubfoot After Walking Age. J Bone Joint Surg Am 2016;98:1706-12.

46. Riganti S, Coppa V, Nasto LA, et al. Treatment of complex foot deformities with hexapod external fixator in growing children and young adult patients. Foot Ankle Surg 2019;25:623-9. 